\title{
Error propagation in equations for geochemical modeling of radiogenic isotopes in two-component mixing
}

\author{
SURENDRA P VERMA \\ Centro de Investigación en Energía, UNAM, Priv. Xochicalco S/N, Col. Centro, \\ Apartado Postal 34, Temixco, Mor. 62580, Mexico. \\ email: spv@mazatl.cie.unam.mx
}

\begin{abstract}
This paper presents error propagation equations for modeling of radiogenic isotopes during mixing of two components or end-members. These equations can be used to estimate errors on an isotopic ratio in the mixture of two components, as a function of the analytical errors or the total errors of geological field sampling and analytical errors. Two typical cases ("Small errors" and "Large errors") are illustrated for mixing of Sr isotopes. Similar examples can be formulated for the other radiogenic isotopic ratios. Actual isotopic data for sediment and basalt samples from the Cocos plate are also included to further illustrate the use of these equations. The isotopic compositions of the predicted mixtures can be used to constrain the origin of magmas in the central part of the Mexican Volcanic Belt. These examples show the need of high quality experimental data for them to be useful in geochemical modeling of magmatic processes.
\end{abstract}

\section{Introduction}

Data reduction and error analysis have become fundamental in physical and chemical sciences (e.g., Bevington 1969; Taylor 1990; Guedens et al 1993a, b). Error evaluation and propagation are a routine matter in geochronology and isotope geology (Dalrymple and Lanphere 1969; Faure 1986; Rollinson 1993; Dickin 1995), but have not attracted adequate attention in other branches of earth sciences, such as trace element determination and modeling of magmatic processes using these elements (Wilson 1989; López Ruiz and Cebriá Gómez 1990; Albarède 1995, Verma 1996a). For major element mass-balance modeling, leastsquares regression techniques are routinely applied in geochemistry (e.g. Bryan et al 1969; Wright and Doherty 1970; Albarède and Provost 1977; Verma et al 1992).

In petrological and thermodynamic problems, error analysis has gained importance as evidenced in several books (Le Maitre 1982; Taylor 1982; McBirney 1984; Ragland 1989; Rollinson 1993). Error propagation theory has been applied recently to geothermal research for evaluating three geothermometers and proposing new geothermometric equations from outlier detection and elimination (Santoyo and Verma 1991, 1993; Verma and Santoyo 1995, 1997).

Accuracy and precision provide two parameters to assess analytical errors. For isotopic ratios, precision is generally estimated in each sample run (expressed as $2 \sigma_{E}$; two times the standard error of the mean), but can also be determined by replicate analyses. Accuracy is also controlled by running an "accepted" standard several times during the course of a study and adjusting the isotopic ratios of unknown samples for a probable instrumental bias in isotopic determinations. For trace elements, on the other hand, the precision and accuracy are generally estimated by analyzing an international geochemical reference material (RM). Unfortunately, most RM still show a large spread of elemental data (e.g., Gladney and Roelandts, 1988; Govindaraju et al 1994; Imai et al 1995; Velasco and Verma 1998), although better-characterized mean concentration values can be obtained by a procedure

Keywords. Isotopic ratios; geochemistry; error propagation; mixing; Mexico; Cocos plate. 
involving a large number of statistical tests for outlier detection and rejection (Verma 1996b, 1997, 1998; Verma et al 1998). Quality-value parameter based on the relative standard deviation of the final data population can be used to decide the usefulness of these RM to specific analytical problems (Potts and Kane 1992; Verma 1997). It is not customary to adjust the trace element data for possible bias, although statistical tests are sometimes applied for establishing new methods or for testing the quality of data from existing analytical procedures (Sutarno and Steger 1985; Velasco and Verma 1995).

The errors of trace element determination in individual geological samples are therefore not precisely known. It is however not difficult to estimate the precision of individual analysis, using error propagation theory (Bevington 1969; Guedens et al 1993a, b; Verma 1995). In fact, this has been done for mass spectrometric isotope dilution measurements (Verma 1981; Verma and Schilling 1982).

The consequences of the experimental errors inherent in the determination of trace elements and isotopic ratios have not been evaluated for modeling of igneous processes, such as partial melting (Schilling and Winchester 1967; Gast 1968; Shaw 1970, Hertogen and Gijbels 1976; Hanson 1978; Albarède 1983; Maaløe 1994), fractional crystallization (Neumann et al 1954; Greenland 1970; Albarède 1976; Allègre and Minster 1978; Langmuir 1989; O'Hara and Fry 1996a, b), magma mixing or source mixing (Anderson 1976; Langmuir et al 1978; DePaolo and Wasserburg 1979; Myres et al 1987; López Ruiz and Cebriá Gómez 1990), and combined assimilation and fractional crystallization (Taylor 1980; DePaolo 1981, 1985; Powell 1984; Taylor and Sheppard 1986; Hagen and Neumann 1990). Recently, although Albarède (1995) has presented some worked examples, systematic work, reporting explicit error propagation equations and illustrative examples, is in fact required for a more extensive application of these concepts in geochemistry.

A series of papers will be devoted to analyze the consequences of experimental errors inherent in the determination of trace elements and isotopic ratios for modeling of igneous processes. This first part deals with error propagation for isotopic ratios in twocomponent mixtures. The case of inverse modeling in which the composition of one or both components or end-members is predicted from the composition of several mixture samples will be presented elsewhere.

\section{New error equations for two-component mixing}

Error propagation theory provides the rules for combining errors of two variables related to each other by a mathematical operation, such as summa- tion, subtraction, multiplication, and division, or for a variable involved in a mathematical function, such as exponent or logarithm (Bevington 1969; Taylor 1982; Guedens et al 1993a, b). New equations are derived from this theory by propagating errors of different parameters involved in geochemical modeling of mixing of two components. The resulting equations express explicitly the error of the predicted variable (isotopic ratio in the mixture) in terms of the errors in the initial variables (e.g., original concentration of the corresponding trace element and isotopic ratio of the two components). These equations predict the uncertainty in the composition of the mixture of two components, prior to its possible modification from other processes that might take place after the mixing has been completed.

\subsection{Equations for an isotopic ratio}

As many other igneous processes, the mixing process is controlled by mass-balance. For radiogenic isotopes, such as ${ }^{87} \mathrm{Sr} /{ }^{86} \mathrm{Sr},{ }^{143} \mathrm{Nd} /{ }^{144} \mathrm{Nd},{ }^{206} \mathrm{~Pb} /{ }^{204} \mathrm{~Pb}$, etc., the mixing of two components is given by equations similar to the ones developed here for ${ }^{87} \mathrm{Sr} /{ }^{86} \mathrm{Sr}$.

For mixing of Sr concentration, the mixing equations (Faure 1986) of element concentration will not be strictly applicable in their present form, as the atomic weight depends on the actual value of the isotopic ratio of radiogenic $\mathrm{Sr}$ (i.e., ${ }^{87} \mathrm{Sr} /{ }^{86} \mathrm{Sr}$ ). However, the differences in atomic weights are generally very small as shown below.

The element $\mathrm{Sr}$ consists of four stable isotopes (Faure 1986): ${ }^{88} \mathrm{Sr},{ }^{87} \mathrm{Sr},{ }^{86} \mathrm{Sr}$, and ${ }^{84} \mathrm{Sr}$. One of them $\left.{ }^{87} \mathrm{Sr}\right)$ is radiogenic and therefore has a variable abundance. The absolute abundance of these isotopes can be obtained from the measured isotopic ratios of different isotopes of Sr. As an example, let us assume for a sample that ${ }^{87} \mathrm{Sr} /{ }^{86} \mathrm{Sr}=0.710$ (crust-type $\mathrm{Sr}$ ), ${ }^{86} \mathrm{Sr} /{ }^{88} \mathrm{Sr}=0.1194$ (by definition, this value is used in corrections of isotopic fractionation effects), and ${ }^{84} \mathrm{Sr} /{ }^{88} \mathrm{Sr}=0.006756$. Using the atomic masses of the isotopes ${ }^{88} \mathrm{Sr}=87.905625 \mathrm{amu},{ }^{87} \mathrm{Sr}=86.908890$ $\mathrm{amu},{ }^{86} \mathrm{Sr}=85.909273 \mathrm{amu}$, and ${ }^{84} \mathrm{Sr}=83.913428$ amu (Walker et al 1977), it is a simple matter to show that the atomic weight of such a $\mathrm{Sr}$ is $87.6167 \mathrm{amu}$. If the ${ }^{87} \mathrm{Sr} /{ }^{86} \mathrm{Sr}$ in the sample were 0.703 (mantle-type $\mathrm{Sr}$ ), then the atomic weight of such a Sr will be 87.6172 amu, not very different from crust-type Sr. The differences are thus too small to be of much significance in modeling of magmatic processes described in this paper.

The equations are simpler if one assumes very similar, almost identical atomic weights of $\mathrm{Sr}$ and absolute abundance of ${ }^{86} \mathrm{Sr}$ in components $A$ and $B$. This assumption is generally justified as shown above for all cases where the isotopic ratios of the two endmembers are not drastically different. The mixing equation for the isotopic ratio is as follows (e.g., Faure 
1986, Albarède 1995):

$$
\left(\frac{{ }^{87} \mathrm{Sr}}{{ }^{86} \mathrm{Sr}}\right)_{M}=\frac{f \operatorname{Sr}_{A}\left(\frac{{ }^{87} \mathrm{Sr}}{{ }^{86} \mathrm{Sr}}\right)_{A}+(1-f) \operatorname{Sr}_{B}\left(\frac{{ }^{87} \mathrm{Sr}}{86 \mathrm{Sr}}\right)_{B}}{f \mathrm{Sr}_{A}+(1-f) \operatorname{Sr}_{B}}
$$

where $\mathrm{Sr}_{A}$ and $\mathrm{Sr}_{B}$ are the concentrations of $\mathrm{Sr}$ in components $A$ and $B$ respectively; $f$ is the fraction of the component $A$ in the mixture. The concentration of $\mathrm{Sr}$ in the mixture $\mathrm{Sr}_{M}$ is estimated as follows:

$$
\mathrm{Sr}_{M}=f \mathrm{Sr}_{A}+(1-f) \mathrm{Sr}_{B} .
$$

For convenience, I define two new variables $\alpha$ and $\beta$ as follows:

$$
\begin{aligned}
& \alpha=f \operatorname{Sr}_{A}\left(\frac{{ }^{87} \mathrm{Sr}}{{ }^{86} \mathrm{Sr}}\right)_{A}, \\
& \beta=(1-f) \operatorname{Sr}_{B}\left(\frac{{ }^{87} \mathrm{Sr}}{{ }^{86} \mathrm{Sr}}\right)_{B} .
\end{aligned}
$$

Using equations (2) to (4), the equation (1) can be written simply as:

$$
\left(\frac{{ }^{87} \mathrm{Sr}}{{ }^{86} \mathrm{Sr}}\right)_{M}=\frac{\alpha+\beta}{\mathrm{Sr}_{M}} .
$$

Both the concentration and isotopic ratio are characterized by experimental errors, although the former error (for concentration) is generally much greater than the latter one (for isotopic ratio). Let $\sigma_{A}^{\mathrm{Sr}}$ and $\sigma_{A}^{87 / 86}$ be the respective errors for component $A$; $\sigma_{B}^{\mathrm{Sr}}$ and $\sigma_{B}^{87 / 86}$ for component $B ; \sigma_{M}^{\mathrm{Sr}}$ and $\sigma_{M}^{87 / 86}$ for the mixture $M$. In many practical cases, these errors could be total sampling and experimental errors. In other words, they could represent the actual variability of heterogeneous end-members, provided their distribution is not too different from a "normal" statistical sample.

The general error propagation equation for $\mathrm{Sr}_{M}$ is:

$$
\sigma_{M}^{\mathrm{Sr}^{2}}=f^{2} \sigma_{A}^{\mathrm{Sr}^{2}}+(1-f)^{2} \sigma_{B}^{\mathrm{Sr}^{2}}+2 f(1-f) \sigma_{A B}^{\mathrm{Sr}}
$$

where $\sigma_{A B}^{\mathrm{Sr}}$ is the covariance of $\mathrm{Sr}$ concentration in the components $A$ and $B$.

The covariance term should tend to zero because, in practically all cases, the measurements of $\mathrm{Sr}$ concentration in the two components $A$ and $B$ are independent and therefore $\sigma_{A B}^{\mathrm{Sr}} \rightarrow 0$. In that case, the equation (6) reduces to:

$$
\sigma_{M}^{\mathrm{Sr}^{2}}=f^{2} \sigma_{A}^{\mathrm{Sr}^{2}}+(1-f)^{2} \sigma_{B}^{\mathrm{Sr}^{2}} .
$$

The general error propagation equation for $\operatorname{Sr}_{M}^{87 / 86}$ is:

$$
\left(\sigma_{M}^{86 / 86}\right)^{2}=\left(\frac{{ }^{87} \mathrm{Sr}}{{ }^{86} \mathrm{sr}}\right)_{M}^{2}\left[\frac{\sigma_{u}^{2}}{u^{2}}+\frac{\sigma_{v}^{2}}{v^{2}}-2 \frac{\sigma_{u v}}{u v}\right]
$$

where

$$
u=\alpha+\beta .
$$

Neglecting the covariance term (as the determinations of $\mathrm{Sr}$ concentration and ${ }^{87} \mathrm{Sr} /{ }^{86} \mathrm{Sr}$ in the components $A$ and $B$ are independent),

$$
\begin{aligned}
\sigma_{u}^{2}= & \alpha^{2}\left[\left\{\frac{\sigma_{A}^{\mathrm{Sr}}}{\mathrm{Sr}_{A}}\right\}^{2}+\left\{\frac{\sigma_{A}^{87 / 86}}{\left(\frac{{ }^{87} \mathrm{Sr}}{{ }^{86} \mathrm{Sr}}\right)_{A}}\right\}^{2}\right] \\
& +\beta^{2}\left[\left\{\frac{\sigma_{B}^{\mathrm{Sr}}}{\mathrm{Sr}_{B}}\right\}^{2}+\left\{\frac{\sigma_{B}^{87 / 86}}{\left(\frac{{ }^{87} \mathrm{Sr}}{{ }^{86} \mathrm{Sr}}\right)_{B}}\right\}^{2}\right] \\
v= & \operatorname{Sr}_{M} \\
\sigma_{v}^{2}= & f^{2} \sigma_{A}^{\mathrm{Sr}^{2}}+(1-f)^{2} \sigma_{B}^{\mathrm{Sr}^{2}} .
\end{aligned}
$$

Although Bevington (1969) used $\sigma_{u v}^{2}$ to denote covariance of the variables $u$ and $v$, Taylor (1982) encouraged the use of the term $\sigma_{u v}$, simply because the covariance can be negative and that $\sigma_{u v}$ has the dimensions of $u v$. The latter notation is therefore used in this paper. The covariance $\sigma_{u v}$ is given by,

$$
\sigma_{u v}=\langle(u-\bar{u})(v-\bar{v})\rangle .
$$

The variables $u$ and $v$ are respectively the numerator and denominator of the right hand side of equation (5). The covariance can be expressed as Schwarz inequality (Taylor 1982):

$$
\left|\sigma_{u v}\right| \leq \sigma_{u} \sigma_{v} .
$$

If it is assumed that these two variables $u$ and $v$ are "perfectly" correlated, then the inequality (14) can be written as equality equation (15):

$$
\left|\sigma_{u v}\right|=\sigma_{u} \sigma_{v}
$$

and therefore equation (8) can be modified as,

$$
\left(\sigma_{M}^{87 / 86}\right)_{\min }^{2}=\left(\frac{{ }^{87} \mathrm{Sr}}{86 \mathrm{Sr}}\right)_{M}^{2}\left[\frac{\sigma_{u}^{2}}{u^{2}}+\frac{\sigma_{v}^{2}}{v^{2}}-2 \frac{\sigma_{u} \sigma_{v}}{u v}\right]
$$

or, simplifying one can obtain

$$
\left(\sigma_{M}^{87 / 86}\right)_{\min }=\left(\frac{{ }^{87} \mathrm{Sr}}{{ }^{86} \mathrm{Sr}}\right)_{M}\left[\frac{\sigma_{u}}{u}-\frac{\sigma_{v}}{v}\right] .
$$

Equation (17) gives the minimum error of ${ }^{87} \mathrm{Sr} /{ }^{86} \mathrm{Sr}$ in the mixture of $A$ and $B$, in the case when the variables $u$ and $v$ are perfectly correlated.

The general case is when the variables $u$ (numerator) and $v$ (denominator) of the right hand side of equation (1) are not perfectly correlated. Although the concentration terms $\mathrm{Sr}_{A}$ and $\mathrm{Sr}_{B}$ are present in both numerator and denominator, the isotopic terms $\left({ }^{87} \mathrm{Sr} /{ }^{86} \mathrm{Sr}\right)_{A}$ and $\left({ }^{87} \mathrm{Sr} /{ }^{86} \mathrm{Sr}\right)_{B}$ occur only in the numerator. Therefore, the variations of the concentration variables will contribute to the covariance term $\sigma_{u v}$, leaving the effects of the isotopic variables almost negligible in this term. A reasonable estimate 
of this covariance can thus be made from equation (18) below:

$$
\left|\sigma_{u v}\right| \approx\left(\sigma_{u}\right)_{\mathrm{cov}}\left(\sigma_{v}\right)_{\mathrm{cov}}
$$

where $\left(\sigma_{u}\right)_{\operatorname{cov}}$ and $\left(\sigma_{v}\right)_{\text {cov }}$ are approximated as follows for this covariance term only:

$$
\begin{aligned}
& \left(\sigma_{u}\right)^{2}=\sqrt{\alpha^{2}\left[\left\{\frac{\sigma_{A}^{\mathrm{Sr}}}{\mathrm{Sr}_{A}}\right\}^{2}\right]+\beta^{2}\left[\left\{\frac{\sigma_{B}^{\mathrm{Sr}}}{\mathrm{Sr}_{B}}\right\}^{2}\right]}, \\
& \left(\sigma_{v}\right)_{\mathrm{cov}}=\sqrt{f^{2} \sigma_{A}^{\mathrm{Sr}^{2}}+(1-f)^{2} \sigma_{B}^{\mathrm{Sr}^{2}}} .
\end{aligned}
$$

Therefore, the final error can be estimated from equation (21), using equations (10) and (12) as well as (18) to $(20)$.

$$
\left(\sigma_{M}^{87 / 86}\right)^{2} \approx\left(\frac{{ }^{87} \mathrm{Sr}}{{ }^{86} \mathrm{Sr}}\right)_{M}^{2}\left[\frac{\sigma_{u}^{2}}{u^{2}}+\frac{\sigma_{v}^{2}}{v^{2}}-2 \frac{\left(\sigma_{u}\right)_{\mathrm{cov}}\left(\sigma_{v}\right)_{\mathrm{cov}}}{u v}\right] .
$$

\section{Results and discussion}

Equation (21) is for propagated error, whereas equation (17) gives a minimum estimate of this error. Equation (21) should therefore provide a more realistic estimate of the propagated error. It will be used to characterize the mixtures with propagated errors in predicted variables of radiogenic isotopic ratios for two-component mixing. As stated above, sample variability reflecting its heterogeneity can be used in place of experimental errors, unless there is strong evidence that the parameter distribution is not symmetrical. Myers et al (1987) presented a mathematical-graphical procedure to take into account such end-member variability. Instead of this approach, the equations derived here are used to understand and predict the effects of such variability.

\subsection{Illustrative examples of application to radiogenic isotopes}

In order to keep the paper short I will use the $\mathrm{Sr}$ isotopes for illustrative purposes. Similar examples can be put forth for other radiogenic isotopes $\left({ }^{143} \mathrm{Nd} /{ }^{144} \mathrm{Nd},{ }^{206} \mathrm{~Pb} /{ }^{204} \mathrm{~Pb},{ }^{207} \mathrm{~Pb} /{ }^{204} \mathrm{~Pb}\right.$, and ${ }^{208} \mathrm{~Pb} /$ ${ }^{204} \mathrm{~Pb}$ ). In fact, it will be done so in the next section for the actual data from the Cocos plate.

As an example, $\mathrm{Sr}_{A}=10 \mathrm{ppm}, \mathrm{Sr}_{B}=100 \mathrm{ppm}$, $\left({ }^{87} \mathrm{Sr} /{ }^{86} \mathrm{Sr}\right)_{A}=0.703$, and $\left({ }^{87} \mathrm{Sr} /{ }^{86} \mathrm{Sr}\right)_{B}=0.720$ are assumed. The predicted $\mathrm{Sr}$ isotopic ratio $\left({ }^{87} \mathrm{Sr} /{ }^{86} \mathrm{Sr}\right)_{M}$ of a mixture of these two components or end-members $A$ and $B$ as a function of $f$ ( $f$ is the proportion of the component $A$ in the mixture) is plotted in figure 1. This is a general mixing curve for isotopes. Its curvature depends on the relative value of the ratio of the end-member concentrations. Only in the special

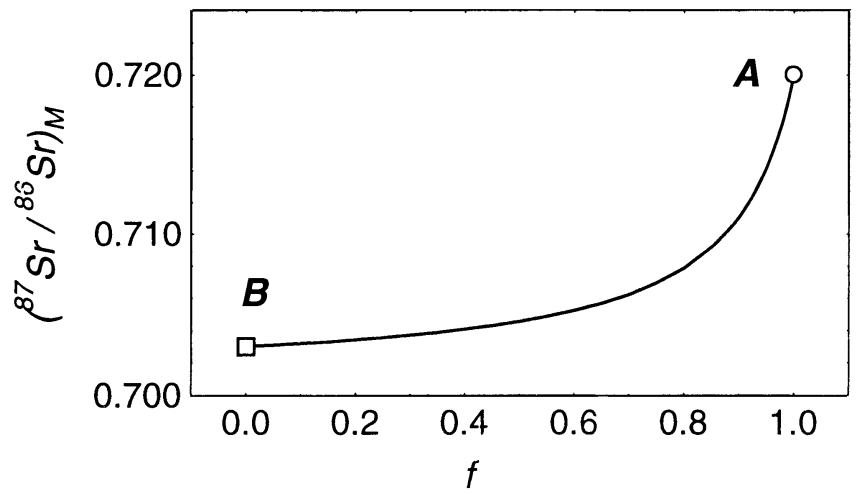

Figure 1. Predicted Sr isotopic ratio $\left({ }^{87} \mathrm{Sr} /{ }^{86} \mathrm{Sr}\right)_{M}$ of a mixture of two components or end-members $A$ and $B$ as a function of $f$ ( $f$ is the proportion of the component $\mathrm{A}$ in the mixture). $\mathrm{Sr}_{A}=10 \mathrm{ppm}, \mathrm{Sr}_{B}=100 \mathrm{ppm},\left({ }^{87} \mathrm{Sr} /{ }^{86} \mathrm{Sr}\right)_{A}=0.703$ and $\left({ }^{87} \mathrm{Sr} /\right.$ $\left.{ }^{86} \mathrm{Sr}\right)_{B}=0.720$ are assumed for this example. The component $A$ is represented by a circle and the component $B$ by a square in this and later diagrams. Note the mixing curve is, in general, not a straight line on this diagram.

circumstance when $\operatorname{Sr}_{A}=\operatorname{Sr}_{B}$ that this mixing curve becomes a straight line. No error bars are shown in this diagram. It therefore represents only the mixing of two totally homogenous and error-free end-members. However, this is a highly improbable situation, as the end-member compositions will generally be variable and also characterized by experimental error, or both sampling and experimental errors, reflecting end-member heterogeneity. The propagated error $\sigma_{A}^{87 / 86}$ on the ${ }^{87} \mathrm{Sr} /{ }^{86} \mathrm{Sr}$ of the mixture as a function of $f$ for the example of figure 1 is given in figure 2. The experimental errors of $\mathrm{Sr}$ concentrations are totally correlated, as explained above, and therefore seem to cancel out from the mixture ${ }^{87} \mathrm{Sr} /{ }^{86} \mathrm{Sr}$. The errors on the isotopic ratios are therefore reflected in the final propagated error on the ${ }^{87} \mathrm{Sr} /{ }^{86} \mathrm{Sr}$ in the mixture. Two extreme cases can be considered.

\subsubsection{Small errors}

This case is computed for $\sigma_{A}^{87 / 86}=0.01 \%$ and $\sigma_{B}^{87 / 86}=$ $0.01 \%$. Figure 2(a) gives the mixing curve with error bars and figure $2(\mathrm{~b})$ shows (\%Rsd) ${ }_{M}$ vs. $f$ curve for the same data as in figure 2(a). It is of interest to see how the equal errors of the end-members are propagated to lower errors in the mixture isotopic ratio (figure 2(b)). This behavior depends on the difference between the actual isotopic ratios of the two end-members. In this case of small errors, the size of the symbols generally used in such diagrams is sufficient to represent the propagated errors.

\subsubsection{Large errors}

$\left({ }^{87} \mathrm{Sr} /{ }^{86} \mathrm{Sr}\right)_{M}$ vs. $f$ curve with resulting $\sigma_{M}^{87 / 86}$ vertical error bars for $\sigma_{A}^{87 / 86}=0.16 \%$ and $\sigma_{B}^{87 / 86}=0.08 \%$ is 

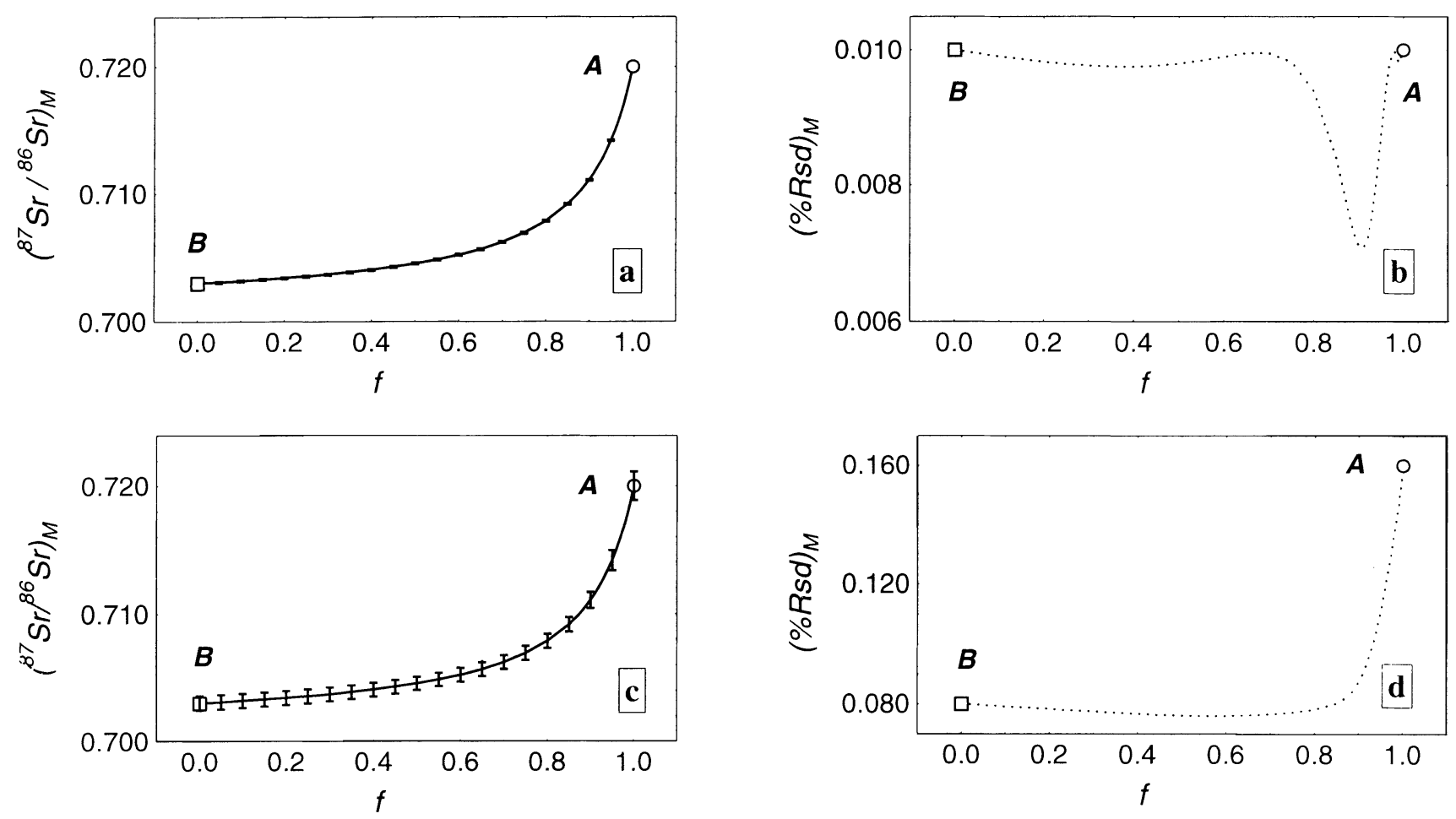

Figure 2. Propagated error $\sigma_{M}^{87 / 86}$ on the ${ }^{87} \mathrm{Sr} /{ }^{86} \mathrm{Sr}$ of the mixture as a function of $f$ for the example of figure 1 " "Small errors" example: (a) $\left.{ }^{87} \mathrm{Sr} /{ }^{86} \mathrm{Sr}\right)_{M}$ vs. $f$ curve with resulting $\sigma_{M}^{87 / 86}$ vertical error bars for both $\sigma_{A}^{87 / 86}=0.01 \%$ and $\sigma_{B}^{87 / 86}=0.01 \%($ the experimental errors of $\mathrm{Sr}$ are totally correlated and seem to cancel out from the mixture ${ }^{87} \mathrm{Sr} /{ }^{86} \mathrm{Sr}$; see text for more explanation); (b) $(\% \text { Rsd })_{M}$ vs. $f$ curve for the same data as in figure $2\left(\right.$ a). "Large errors" example: (c) $\left({ }^{87} \mathrm{Sr} /{ }^{86} \mathrm{Sr}\right)_{M}$ vs. $f$ curve with resulting $\sigma_{M}^{87 / 86}$ vertical error bars for $\sigma_{A}^{87 / 86}=0.16 \%$ and $\sigma_{B}^{87 / 86}=0.08 \%$; (d) $(\% \operatorname{Rsd})_{M}$ vs. $f$ curve for the same data as in figure $2(\mathrm{c})$.

shown in figure $2(\mathrm{c})$. The corresponding $(\% \text { Rsd })_{M}$ vs. $f$ curve for the data of figure $2(\mathrm{c})$ is presented in figure $2(\mathrm{~d})$. The propagated error in this case is somewhat larger than the size of the symbols used. For this case of unequal large errors, the propagated error lies between the two values for the end-members.

\subsection{Application to isotopic ratios from the Cocos plate}

Radiogenic isotopes and related trace element data are summarized in table 1, taken from Verma (1992, 1999) and Leggett (1981). The more important statistical parameters are also included for their use

Table 1.Isotopic and relevant trace element data (with total geological field sampling and analytical errors, reflecting heterogeneity of the compositions) in sediment and altered basalt samples from DSDP Site 487 located at the Cocos plate, Mexico (summarized from Verma 1998b)

\begin{tabular}{|c|c|c|c|c|c|c|c|c|}
\hline \multirow{2}{*}{$\begin{array}{l}\text { Isotopic ratio/ } \\
\text { element }\end{array}$} & \multicolumn{4}{|c|}{ Sediment } & \multicolumn{4}{|c|}{ Basalt } \\
\hline & $n$ & $(\chi)_{A}$ & $\pm \mathrm{S}_{A}$ & $(\% \operatorname{Rsd})_{A}$ & $n$ & $(\chi)_{B}$ & $\pm \mathrm{S}_{B}$ & $(\% \text { Rsd })_{B}$ \\
\hline${ }^{87} \mathrm{Sr} /{ }^{86} \mathrm{Sr}$ & 9 & 0.70851 & \pm 0.00041 & 0.06 & 6 & 0.70324 & \pm 0.00008 & 0.011 \\
\hline${ }^{143} \mathrm{Nd} /{ }^{144} \mathrm{Nd}$ & 9 & 0.51251 & \pm 0.00003 & 0.006 & 6 & 0.51322 & \pm 0.00003 & 0.006 \\
\hline${ }^{206} \mathrm{~Pb} /{ }^{204} \mathrm{~Pb}$ & 2 & 18.74 & \pm 0.21 & 1.1 & 2 & 18.22 & \pm 0.25 & 1.4 \\
\hline${ }^{207} \mathrm{~Pb} /{ }^{204} \mathrm{~Pb}$ & 2 & 15.61 & \pm 0.05 & 0.32 & 2 & 15.50 & \pm 0.07 & 0.45 \\
\hline${ }^{208} \mathrm{~Pb} /{ }^{204} \mathrm{~Pb}$ & 2 & 38.50 & \pm 0.27 & 0.7 & 2 & 37.75 & \pm 0.42 & 1.1 \\
\hline $\mathrm{Sr}$ & $*$ & 204 & \pm 2 & 1.0 & $*$ & 65 & \pm 1 & 1.5 \\
\hline $\mathrm{Rb}$ & * & 92 & \pm 2 & 2.2 & $*$ & 3.0 & \pm 0.2 & 6.7 \\
\hline $\mathrm{Nd}$ & 7 & 26 & \pm 15 & 58 & 5 & 4.2 & \pm 0.6 & 13 \\
\hline $\mathrm{Sm}$ & 7 & 5.6 & \pm 3.3 & 59 & 5 & 1.47 & \pm 0.13 & 8.8 \\
\hline $\mathrm{Pb}$ & 42 & 105 & \pm 25 & 24 & 2 & 0.18 & \pm 0.05 & 28 \\
\hline
\end{tabular}

$\mathrm{S}_{A}$ and $\mathrm{S}_{B}$ are one standard deviation values of isotopic ratio or element concentration data $(\chi)_{A}$ and $(\chi)_{B}$ respectively; $(\% \text { Rsd })_{A}$ and $(\% \text { Rsd })_{B}$ are the relative standard deviations in $\%$ of the components $A$ and $B$ respectively; $n$ is the number of data on which the average and standard deviations are based. Sr and Rb concentration data $\left(n={ }^{*}\right)$ were obtained in sediment and altered basalt composite samples. Each of them was a physical mixture of equal weights of six samples from Site 487 (Verma 1999). Pb concentration data for sediments are summarized from Leggett (1981) and for basalt from Verma (1992). 
Table 2. Predicted isotopic ratios (with their errors or variability estimated from the error propagation theory) in mixtures of sediment and altered basalt samples from the Cocos plate, Mexico

\begin{tabular}{|c|c|c|c|c|c|c|c|c|c|}
\hline \multirow[b]{2}{*}{ Ratio } & \multicolumn{3}{|c|}{ M1S } & \multicolumn{3}{|c|}{ M5S } & \multicolumn{3}{|c|}{ M20S } \\
\hline & $(\chi)_{M}$ & $(\mathrm{~S})_{M}$ & $(\% \mathrm{Rsd})_{M}$ & $(\chi)_{M}$ & $(\mathrm{~S})_{M}$ & $(\% \mathrm{Rsd})_{M}$ & $(\chi)_{M}$ & $(\mathrm{~S})_{M}$ & $(\% \mathrm{Rsd})_{M}$ \\
\hline${ }^{87} \mathrm{Sr} /{ }^{86} \mathrm{Sr}$ & 0.703402 & 0.000079 & 0.011 & 0.703987 & 0.000090 & 0.013 & 0.705557 & 0.000186 & $\overline{0.026}$ \\
\hline${ }^{143} \mathrm{Nd} /{ }^{144} \mathrm{Nd}$ & 0.513178 & 0.000028 & 0.006 & 0.513046 & 0.000055 & 0.011 & 0.512789 & 0.000095 & 0.019 \\
\hline${ }^{206} \mathrm{~Pb} /{ }^{204} \mathrm{~Pb}$ & 18.66 & 0.18 & 1.0 & 18.72 & 0.20 & 1.1 & 18.74 & 0.21 & 1.1 \\
\hline${ }^{207} \mathrm{~Pb} /{ }^{204} \mathrm{~Pb}$ & 15.59 & 0.04 & 0.28 & 15.61 & 0.05 & 0.31 & 15.61 & 0.05 & 0.32 \\
\hline${ }^{208} \mathrm{~Pb} /{ }^{204} \mathrm{~Pb}$ & 38.39 & 0.24 & 0.62 & 38.48 & 0.26 & 0.68 & 38.49 & 0.27 & 0.70 \\
\hline
\end{tabular}

M1S, M5S, and M20S are mixtures of sediment and altered basalt, with respectively 1\%, 5\%, and 20\% sediment components. $(\chi)_{M},(\mathrm{~S})_{M}$, and $(\% \mathrm{Rsd})_{M}$ are respectively the mean isotopic ratio, its propagated error, and relative $\%$ error.
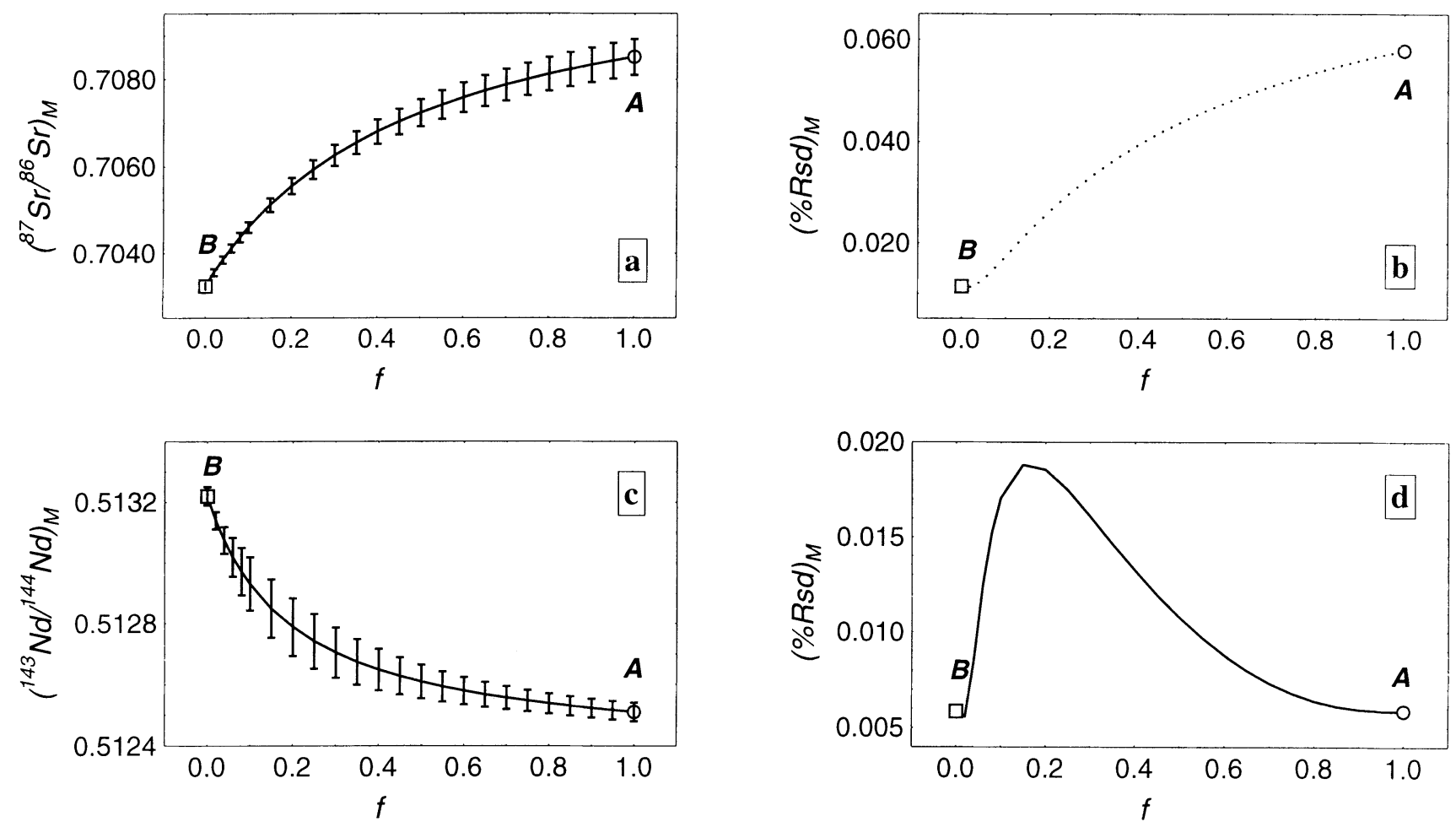

Figure 3. Isotopic compositions of $\mathrm{Sr}$ and $\mathrm{Nd}$ with propagated errors (shown as vertical error bars) as a function of $f$ on predicted mixtures of sediment (component $A$ ) and basalt (component $B$ ), estimated on the basis of the actual data (Verma 1999) from the Cocos plate. (a) $\left.{ }^{87} \mathrm{Sr} /{ }^{86} \mathrm{Sr}\right)_{M}$ vs. $f$ (error bars are $\sigma_{M}^{87 / 86}$ for the predicted mixture); (b) (\%Rsd) ${ }_{M}$ vs. $f$ curve for the same data as in figure 3(a); (c) $\left({ }^{143} \mathrm{Nd} /{ }^{144} \mathrm{Nd}\right)_{M}$ vs. $f$ (error bars are $\sigma_{M}^{143 / 144}$ for the predicted mixture); (d) (\% Rsd) ${ }_{M}$ vs. $f$ curve for the same data as in figure $3(\mathrm{c})$.

in error propagation equations to compute the five radiogenic isotopic compositions of the mixtures with respective propagated errors. The more important results are included in table 2 .

Figure $3(\mathrm{a}-\mathrm{d})$ gives the isotopic compositions of $\mathrm{Sr}$ (figure 3a) and Nd (figure 3c) with propagated errors (figures $3 \mathrm{~b}$ and $3 \mathrm{~d}$ ) as a function of $f$ on predicted mixtures of sediment (component $A$ ) and basalt (component $B$ ) from the Cocos plate. The propagated error on ${ }^{87} \mathrm{Sr} /{ }^{86} \mathrm{Sr}$ varies almost regularly from basalt to sediment (figure $3 \mathrm{~b}$ ), whereas that for ${ }^{143} \mathrm{Nd} /{ }^{144} \mathrm{Nd}$ reaches a maximum for $f \sim 0.15$ (figure $3(\mathrm{~d})$ ).

The isotopic compositions of $\mathrm{Pb}$, with propagated errors $\left(\sigma_{M}^{206 / 204}\right.$ shown as vertical error bars) as a func- tion of $f$ on predicted mixtures of sediment (component $A$ ) and basalt (component $B$ ) from the Cocos plate are shown in figure $4(\mathrm{a}-\mathrm{d})$. Figures $4(\mathrm{a})$ and $4(\mathrm{~b})$ give the $\left({ }^{206} \mathrm{~Pb} /{ }^{204} \mathrm{~Pb}\right)_{M}$ vs. $f$ and $(\% \text { Rsd })_{M}$ vs. $f$ curves, whereas figures $4(\mathrm{c})$ and $4(\mathrm{~d})$ are for $\left({ }^{207} \mathrm{~Pb} /{ }^{204} \mathrm{~Pb}\right)_{M}$ vs. $f$ and $\left({ }^{208} \mathrm{~Pb} /{ }^{204} \mathrm{~Pb}\right)_{M}$ vs. $f$ curves respectively. Here both end-members are highly variable, resulting in very large error bars also for the predicted mixtures.

Figure 5 presents the conventional $\left({ }^{87} \mathrm{Sr} /{ }^{86} \mathrm{Sr}\right)_{M^{-}}$ $\left({ }^{143} \mathrm{Nd} /{ }^{144} \mathrm{Nd}\right)_{M}$ diagram for predicted mixtures of sediment (component $A$ ) and basalt (component $B$ ) from the Cocos plate, but includes the respective error bars representing end-member variability. The error bars $\left(\sigma_{M}^{87 / 86}\right.$ and $\left.\sigma_{M}^{143 / 144}\right)$ correspond to the 

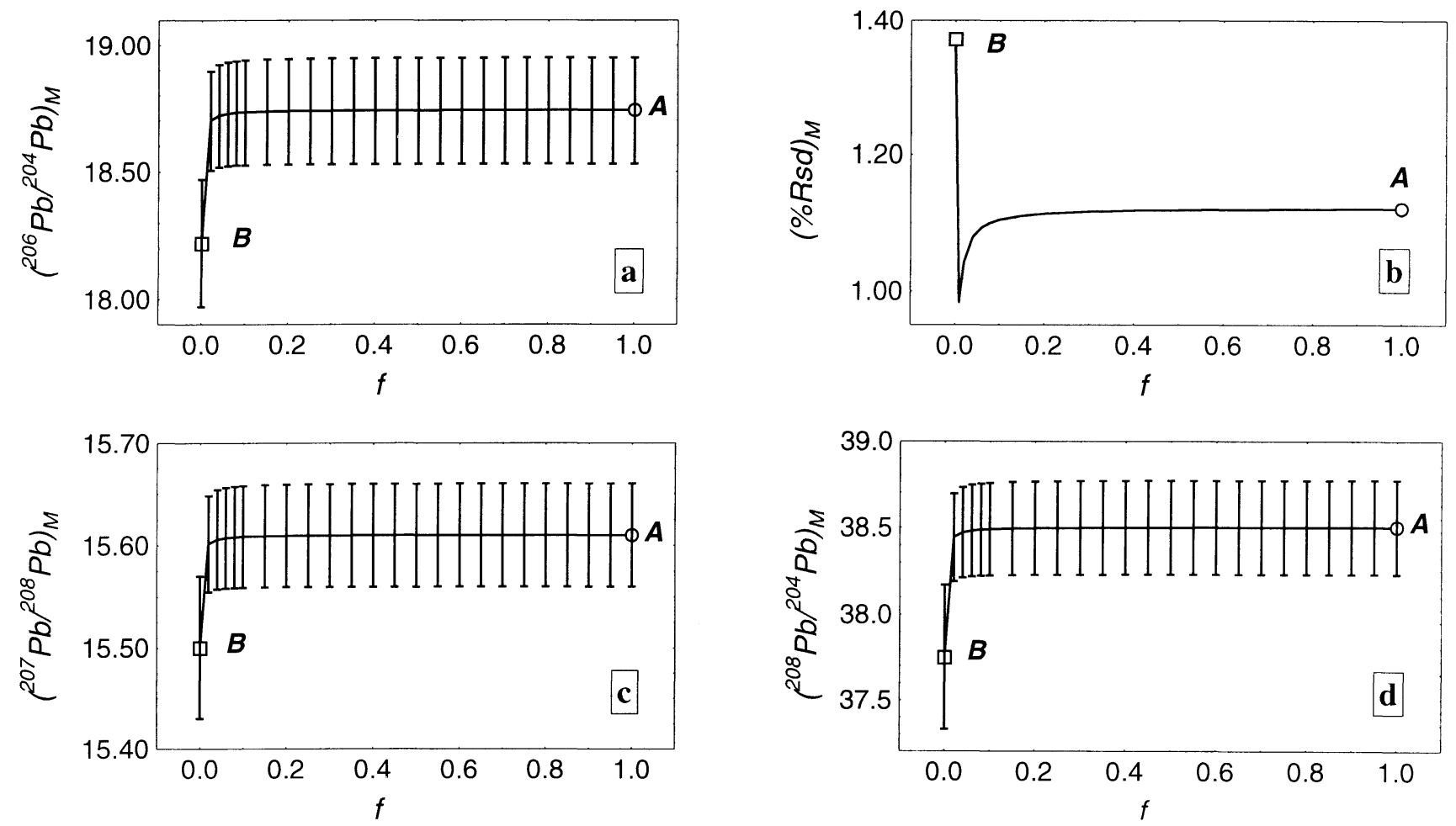

Figure 4. Isotopic compositions of $\mathrm{Pb}$ with propagated errors (shown as vertical error bars) as a function of $f$ on predicted mixtures of sediment (component $A$ ) and basalt (component $B$ ) from the Cocos plate. (a) $\left({ }^{206} \mathrm{~Pb} /{ }^{204} \mathrm{~Pb}\right)_{M}$ vs. $f$ (error bars are $\sigma_{M}^{206 / 204}$ for the predicted mixture); (b) (\%Rsd $)_{M}$ vs. $f$ curve for the same data as in figure $4(\mathrm{a}) ;(\mathbf{c})\left({ }^{207} \mathrm{~Pb} /{ }^{204} \mathrm{~Pb}\right)_{M}$ vs. $f\left(\right.$ error bars are $\sigma_{M}^{207 / 204}$ for the predicted mixture); (d) $\left({ }^{208} \mathrm{~Pb} /{ }^{204} \mathrm{~Pb}\right)_{M}$ vs. $f$ (error bars are $\sigma_{M}^{208 / 204}$ for the predicted mixture).

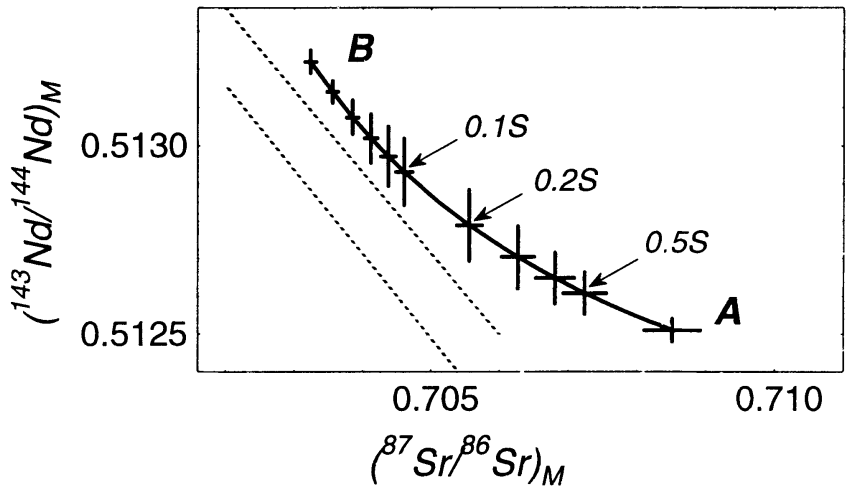

Figure 5. $\left({ }^{87} \mathrm{Sr} /{ }^{86} \mathrm{Sr}\right)_{M}-\left({ }^{143} \mathrm{Nd} /{ }^{144} \mathrm{Nd}\right)_{M}$ diagram for predicted mixtures of sediment (component $A$ ) and basalt (component $B$ ) from the Cocos plate. The error bars are $\sigma_{M}^{87 / 86}$ and $\sigma_{M}^{143 / 144}$ for sediment fractions of 0.00 (pure basalt component), 0.02 , $0.04,0.06,0.08,0.10,0.20,0.30,0.40,0.50$, and 1.00 (pure sediment component). An approximate trace of the "mantle array" is also included for reference (from Rollinson 1993).

sediment fractions of 0.00 (pure basalt component), $0.02,0.04,0.06,0.08,0.10$ (designated $0.1 \mathrm{~S}$ ), 0.20 (designated $0.2 \mathrm{~S}$ ), 0.30, 0.40, 0.50 (designated $0.5 \mathrm{~S}$ ), and 1.00 (pure sediment component). An approximate trace of the "mantle array", included for reference (from Rollinson 1993), shows that the mixing curve for the upper part of the subducting Cocos plate lies far to the right of the most probable mantle compositions. This result has important bearing on the origin of magmas in the central part of the Mexican Volcanic Belt, as most mafic and evolved magmas lie well within the "mantle array" (Verma et al 1991; Verma 1999 and unpublished data). An inescapable conclusion would be that partial melting of the subducting Cocos plate can not generate magmas of the central part of this complex volcanic province.

Some other conventional isotopic diagrams, but with error bars, for predicted mixtures of sediment (component $A$ ) and basalt (component $B$ ) from the Cocos plate are presented in figure $6(\mathrm{a}-\mathrm{d})$. The error bars correspond to the sediment fraction of 0.00 (pure basalt component), 0.01 (designated 0.01S), $0.02,0.05$ (designated $0.05 \mathrm{~S}$ ), 0.10, 0.50, and 1.00 (pure sediment component). Figures 6(a) to 6(d) are respectively for $\left({ }^{87} \mathrm{Sr} /{ }^{86} \mathrm{Sr}\right)_{M^{-}}\left({ }^{206} \mathrm{~Pb} /{ }^{204} \mathrm{~Pb}\right)_{\mathrm{M}}$, $\left({ }^{143} \mathrm{Nd} /{ }^{144} \mathrm{Nd}\right)_{M^{-}}\left({ }^{206} \mathrm{~Pb} /{ }^{204} \mathrm{~Pb}\right)_{M}, \quad\left({ }^{207} \mathrm{~Pb} /{ }^{204} \mathrm{~Pb}\right)_{M^{-}}$ $\left({ }^{206} \mathrm{~Pb} /{ }^{204} \mathrm{~Pb}\right)_{M}$, and $\left({ }^{208} \mathrm{~Pb} /{ }^{204} \mathrm{~Pb}\right)_{M^{-}}\left({ }^{206} \mathrm{~Pb} /{ }^{204} \mathrm{~Pb}\right)_{M}$ mixing curves. The large error bars indicate high variability of the end-members for the $\mathrm{Pb}$ isotopes.

\section{Conclusions}

Error propagation theory is successfully applied to isotopic modeling during mixing of two components in order to predict the effects of analytical errors, or of both sampling and analytical errors. Two probable (extreme) cases identified by "Small errors" and 

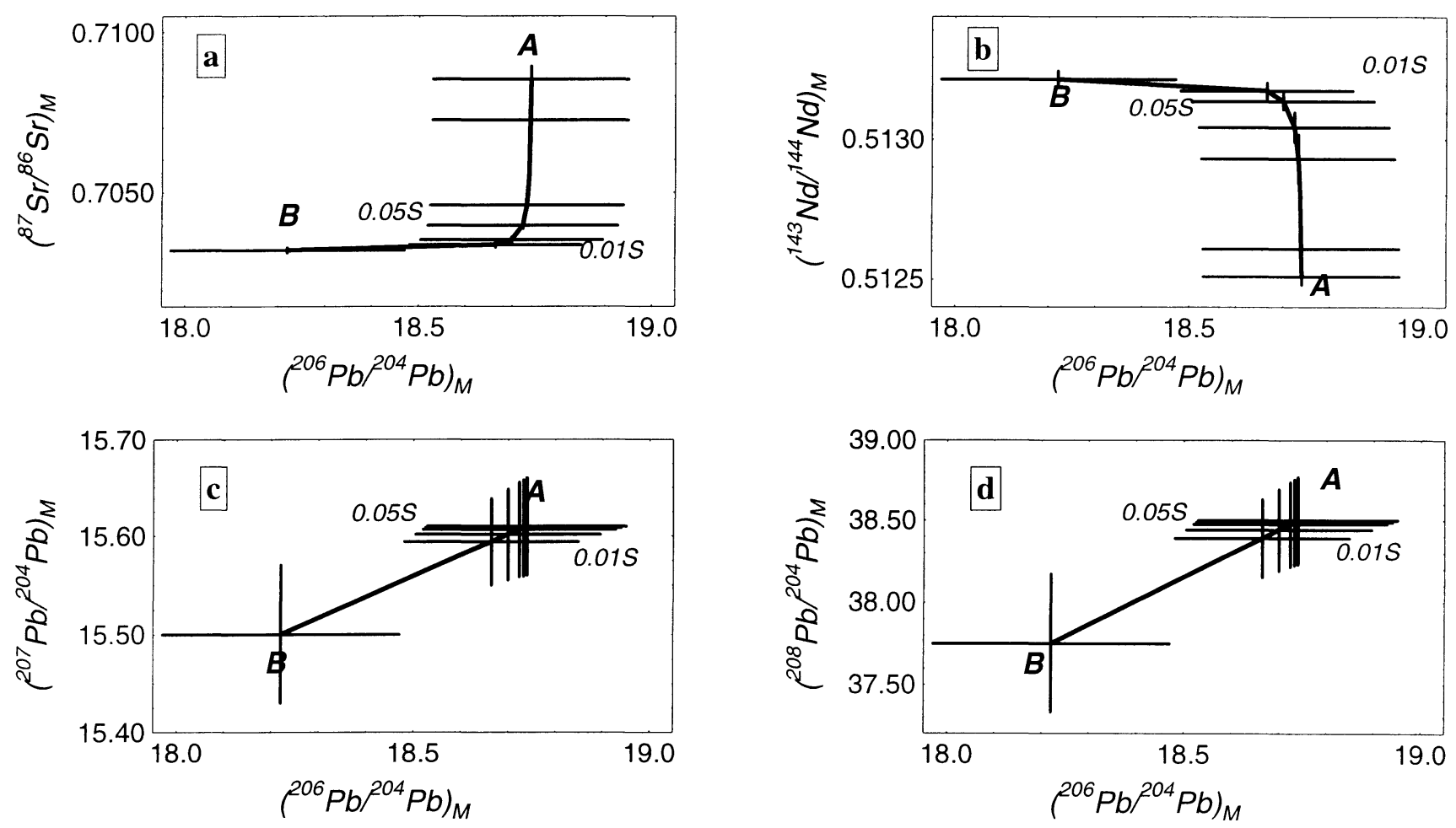

Figure 6. Isotopic diagrams with error bars for predicted mixtures of sediment (component $A$ ) and basalt (component $B$ ) from the Cocos plate. The error bars correspond to the sediment fraction of 0.00 (pure basalt component), 0.01, 0.02, 0.05, 0.10, 0.50, and 1.00 (pure sediment component). (a) $\left.{ }^{87} \mathrm{Sr} /{ }^{86} \mathrm{Sr}\right)_{M}-\left({ }^{206} \mathrm{~Pb} /{ }^{204} \mathrm{~Pb}\right)_{M}$ mixing curve; (b) $\left({ }^{143} \mathrm{Nd} /{ }^{144} \mathrm{Nd}\right)_{M}-\left({ }^{206} \mathrm{~Pb} /{ }^{204} \mathrm{~Pb}\right)_{M}$ mixing curve; (c) $\left({ }^{207} \mathrm{~Pb} /{ }^{204} \mathrm{~Pb}\right)_{M}-\left({ }^{206} \mathrm{~Pb} /{ }^{204} \mathrm{~Pb}\right)_{M}$ mixing curve (straight line); (d) $\left({ }^{208} \mathrm{~Pb} /{ }^{204} \mathrm{~Pb}\right)_{M}-\left({ }^{206} \mathrm{~Pb} /{ }^{204} \mathrm{~Pb}\right)_{M}$ mixing curve (straight line).

"Large errors" are presented to illustrate the use of the newly derived error propagation equations for two-component mixing. The results are presented graphically to show the effect of error propagation in isotopic modeling. Actual examples of radiogenic isotope data from the Cocos plate are presented to demonstrate the usefulness of this approach in isotopic modeling of two component mixing.

\section{Acknowledgements}

This work was partly supported by CONACYT project 0196P-T and DGAPA projects IN-100596 and IN-106199. The manuscript was finalized when the author was visiting CICESE under "Cátedra Patrimonial de Excelencia Nivel 2" (CONACYT) and also served the purpose of teaching some of these quantitative concepts to Geoscience students. This paper is dedicated to Prof. K Gopalan on the occasion of his superannuation from the National Geophysical Research Institute; we shared a common mentor, the Late Prof. V S Venkatasubramanian.

\section{References}

Albarède F 1976 Some trace element relationships amongst liquid and solid phases in the course of the fractional crystallization of magmas; Geochim. Cosmochim. Acta 40 667-673.

Albarède F 1983 Inversion of batch melting equations and the trace element pattern of the mantle; J. Geophys. Res. $\mathbf{8 8}$ 10573-10583.

Albarède F 1995 Introduction to geochemical modeling, (Cambridge, Cambridge University Press) 543 p.

Albarède F and Provost A 1977 Petrological and geochemical mass balance: an algorithm for least-squares fitting and general error analysis; Comput. Geosci. 3 309-326.

Allègre C J and Minster J F 1978. Quantitative models of trace element behavior in magmatic processes; Earth Planet. Sci. Lett. 38 1-25.

Anderson A T 1976 Magma mixing: petrological and volcanological tool; J. Volcanol. Geotherm. Res. 1 3-33.

Bevington P R 1969 Data reduction and error analysis for the physical sciences (New York: McGraw Hill) 336 p.

Bryan W B, Finger L W and Chayes F 1969 Estimating proportions in petrographic mixing equations by least-square approximations; Science 163 926-927

Dalrymple G B and Lanphere M A 1969 Potassium-Argon Dating (San Francisco: Freeman) 258 p.

DePaolo D J 1981 Trace element and isotopic effects of combined wallrock assimilation and fractional crystallization; Earth Planet. Sci. Lett. 53 189-202

DePaolo D J 1985 Isotopic studies of processes in mafic magma chambers; J. Petrol. 4 925-951.

DePaolo D J and Wasserburg G J 1979 Nd isotopic variations and petrogenetic models; Geophys. Res. Lett. 3 249-252

Dickin A P 1995 Radiogenic isotope geology (Cambridge: Cambridge University Press) 490 p.

Faure G 1986 Principles of isotope geology (New York: John Wiley) 589 p. 
Gast P W 1968 Trace element fractionation and the origin of tholeiitic and alkaline magma types; Geochim. Cosmochim. Acta 32, 1057-1086

Gladney E S and Roelandts I 19881987 compilation of elemental concentration data for USGS BIR-1, DNC-1 and W-2; Geostand. Newslett. 12 63-118

Govindaraju K, Potts P J, Webb P C and Watson J S 1994 1994 report on Whin Sill dolerite WS-E and Pittscurrie microgabbro PM-S from Scotland: assessment by one hundred and four international laboratories; Geostand. Newslett. 18 211-300

Greenland L P 1970 An equation for trace element distribution during magmatic crystallization; Am. Mineral. 55 455-465

Guedens W J, Yperman J, Mullens J, Van Poucke L C and Pauwels E J 1993a Statistical analysis of errors: a practical approach for an undergraduate Chemistry lab. Part 1. The concepts; J. Chem. Educ. 70 776-779

Guedens W J, Yperman J, Mullens J, Van Poucke L C and Pauwels E J 1993b Statistical analysis of errors: a practical approach for an undergraduate Chemistry lab. Part 2. Some worked examples; J. Chem. Educ. 70 776-779

Hagen H and Neumann E-R 1990 Modeling of trace element distribution in magma chambers using open-system models; Comput. Geosci. 16 549-556

Hanson G N 1978 The application of trace elements to the petrogenesis of igneous rocks for granitic composition; Earth. Planet Sci. Lett. 38 26-43

Hertogen J and Gijbels R 1976 Calculation of trace element fractionation during partial melting; Geochim. Cosmochim. Acta 40 313-322

Imai N, Terashima S, Itoh S and Ando A 19951994 compilation of analytical data for minor and trace elements in seventeen GSJ geochemical reference samples, "igneous rock series"; Geostand. Newslett. 19 135-213

Langmuir C H 1989 Geochemical consequences of in situ crystallization; Nature 340 199-205

Langmuir C H, Vocke R D, Hanson G N and Hart S R 1978 A general mixing equation with applications to Icelandic basalts; Earth Planet. Sci. Lett. 37 380-392

Leggett J K 1981 Geochemistry of Cocos plate pelagichemipelagic sediments in Hole 487, Deep Sea Drilling Project Leg 66. In: Init. Repts. Deep Sea Drilling Project, (eds) J S Watkins, J C Moore et al (Washington, D.C.: U.S. Government Printing Office) 683-686.

Le Maitre R W 1982 Numerical petrology (Amsterdam: Elsevier)

López Ruiz J and Cebriá Gómez J M 1990 Geoquimica de los Procesos Magmáticos. Madrid: Editorial Rueda 168 p.

Maaløe S 1994 Estimation of the degree of partial melting using concentration ratios; Geochim. Cosmochim. Acta $\mathbf{5 8} 2519$ 2525

McBirney A R 1984 Igneous petrology (San Francisco: Freeman)

Myers J D, Angevine C L and Frost C D 1987 Mass balance calculations with end member compositional variability: applications to petrologic problems; Earth Planet. Sci. Lett. $81212-220$

Neumann H, Mead J and Vitaliano C J 1954 Trace element variations during fractional crystallization as calculated from the distribution law; Geochim. Cosmochim. Acta 6 90-99

O'Hara M J and Fry N 1996a The highly compatible trace element paradox-fractional crystallization revisited; J. Petrol. 37 859-890

O'Hara M J and Fry N 1996b Geochemical effects of small packet crystallization in large magma chambers - further resolution of the highly compatible element paradox; $J$. Petrol. 37 891-925

Potts P J and Kane J S 1992 Terminology for geological reference material values: a proposal to the International
Organization of Standardisation (ISO), producers and users; Geostand. Newslett. 16 133-341

Powell R 1984 Inversion of the assimilation and fractional crystallisation (AFC) equations: characterization of contaminants from isotope and trace element relationships in volcanic suites; J. Geol. Soc. London 141 447-452

Ragland P C 1989 Basic analytical petrology (New York: Oxford University Press)

Rollinson H R 1993 Using geochemical data: evaluation, presentation, interpretation (New York: Wiley) 352 p.

Santoyo E and Verma S P 1991 Evaluación de errores en el uso de los geotermómetros químicos para la prospección de recursos geotérmicos; Actas Fac. Ciencias Tierra UANL Linares 6 5-10

Santoyo E and Verma S P 1993 Evaluación de errores en el uso de los geotermómetros de $\mathrm{SiO}_{2}$ y Na/K para la determinación de temperaturas en sistemas geotérmicos; Geofis. Int. 32 287-298.

Schilling J-G and Winchester J W 1967 Rare-earth fractionation and magmatic processes. In: Mantles of earth and terrestrial planets, (ed) S K Runcorn, 267-283

Shaw D M 1970 Trace element fractionation during anatexis; Geochim. Cosmochim. Acta 34 237-243

Sutarno R and Steger H F 1985 Validation of accuracy by interlaboratory programme; Talanta 32 1088-1091

Taylor H P Jr 1980 The effects of assimilation of country rocks by magmas on ${ }^{18} \mathrm{O} /{ }^{16} \mathrm{O}$ and ${ }^{87} \mathrm{Sr} /{ }^{86} \mathrm{Sr}$ systematics; Earth Planet. Sci. Lett. 47 243-254

Taylor H P, Jr and Sheppard S M F 1986 Igneous Rocks: I. Processes of isotopic fractionation and isotope systematics. In: Stable Isotopes in High Temperature Geological Processes Rev. Mineral, (eds) J M Valley, H P Taylor, Jr. and J R O'Niel, 16: 227-271

Taylor J R 1982 An introduction to error analysis (New York: University Science Books) 270 p.

Taylor J K 1990 Statistical techniques for data analysis. Chelsea, Michigan; Lewis Publishers 200 p.

Velasco F and Verma S P 1995 Aplicación de materiales de referencia en los programas de control de calidad/aseguramiento de calidad en geoquímica; Actas INAGEQ 1 187-192

Velasco F and Verma S P 1998 Importance of skewness and kurtosis statistical tests for outlier detection and elimination in evaluation of geochemical reference materials; Math. Geol. 30 109-128

Verma S P 1981 Mass spectrometric isotope dilution determination of $\mathrm{K}, \mathrm{Rb}, \mathrm{Cs}, \mathrm{Ba}$ and $\mathrm{Sr}$ in five geochemical reference samples; Geostand. Newslett. 5 129-131

Verma S P 1992 Seawater alteration effects on REE, K, Rb, Cs, $\mathrm{Sr}, \mathrm{U}, \mathrm{Th}, \mathrm{Pb}$ and $\mathrm{Sr}-\mathrm{Nd}-\mathrm{Pb}$ isotope systematics of MidOcean Ridge Basalt; Geochem. J., 26 159-177.

Verma S P 1995 Nueva metodología para la evaluación de errores en técnicas analíticas en geoquímica; Actas INAGEQ $1215-220$

Verma S P 1996 Error propagation in trace element modelling of some igneous processes; J. Conf. Abstr. 1649

Verma S P 1996b Evaluation of accuracy in analytical geochemistry; J. Conf. Abstr. 1650

Verma S P 1997 Sixteen statistical tests for outlier detection and rejection in evaluation of international geochemical reference materials: example of microgabbro PM-S; Geostand. Newslett.: J. Geostand. Geoanal. 21 59-75

Verma S P 1998 Improved concentration data in two international geochemical reference materials (USGS basalt BIR-1 and GSJ peridotite JP-1) by outlier rejection; Geofis Int. 37 215-250

Verma S P 1999 Geochemistry of subducting Cocos plate and the origin of subduction-unrelated mafic volcanism at the volcanic front of central Mexican Volcanic Belt; Geol. Soc. 
Am. Spec. Paper on Cenozoic Tectonics and Volcanism of Mexico 334, Chapter 13 (in press)

Verma S P and Santoyo E 1995 New improved equations for $\mathrm{Na} / \mathrm{K}$ and $\mathrm{SiO}_{2}$ geothermometers by error propagation; Proc. World Geotherm. Congr. 2 963-968

Verma S P and Santoyo E 1997 New improved equations for $\mathrm{Na} / \mathrm{K}, \mathrm{Na} / \mathrm{Li}$ and $\mathrm{SiO} 2$ geothermometers by outlier detection and rejection; J. Volcanol. Geotherm. Res. 79 9-23

Verma S P and Schilling J-G 1982 Galapagos Hotspot-Spreading Center system. $2 .{ }^{87} \mathrm{Sr} /{ }^{86} \mathrm{Sr}$ and large ion lithophile element variations $\left(85^{\circ} \mathrm{W}-101^{\circ} \mathrm{W}\right)$; J. Geophys. Res. 87, 10838-10856

Verma S P, Carrasco-Núñez G and Milán M 1991 Geology and geochemistry of Amealco caldera, Qro., Mexico; J. Volcanol. Geotherm. Res. 47 105-127

Verma S P, Navarro-L I and Garcia Cacho L 1992 Majorelement geochemistry and mineralogy of the Huichapan caldera, Hidalgo, Mexico; J. South Am. Earth Sci. 5 327-336

Verma S P, Orduña-Galván J L and Guevara M 1998 SIPVADE: A new computer program with seventeen statistical tests for outlier detection in evaluation of international geochemical reference materials and its application to Whin Sill dolerite WS-E from England and Soil-5 from Peru; Geostand. Newslett.: J. Geostand. Geoanal., 22 209-234

Walker F W, Kiroac G J and Rourke F M 1977 Chart of the Nuclides. Twelfth edition, General Electric, $52 \mathrm{p}$.

Wilson M 1989 Igneous petrogenesis. A global tectonic approach, London: Harper Collins

Wright T L and P C Doherty 1970 A linear programming and least squares computer method for solving petrologic mixing problems; Geol. Soc. Am. Bull. 81 1995-2008 